\title{
Impact of encoding depth on awareness of perceptual effects in recognition memory
}

\author{
JOHN M. GARDINER \\ University of Sussex, Brighton, England \\ VERNON H. GREGG \\ Birkbeck College, University of London, London, England \\ and \\ RESHMA MASHRU and MONICA THAMAN \\ City University, London, England
}

\begin{abstract}
Pictorial stimuli are more likely to be recognized if they are the same size, rather than a different size, at study and at test. This size congruency effect was replicated in two experiments in which the encoding variables were respectively undivided versus divided attention and level of processing. In terms of performance, these variables influenced recognition and did not influence size congruency effects. But in terms of awareness, measured by remember and know responses, these variables did influence size congruency effects. With undivided attention and with a deep level of processing, size congruency effects occurred only in remembering. With divided attention and with a shallow level of processing, size congruency effects occurred only in knowing. The results show that effects that occur in remembering may also occur independently in knowing. They support theories in which remembering and knowing reflect different memory processes or systems. They do not support the theory that remembering and knowing reflect differences in trace strength.
\end{abstract}

Searle (1997) argued forcefully that any explanation of consciousness must explain subjective states of awareness. He also argued that though individual experiences are indeed individual, that does not place them out of scientific reach. Individual experiences become open to science provided the approach is pitched at the level of populations of experiences rather than at the level of unique experiences (Gardiner, 2000). To do this, it becomes necessary to classify experiences, to find grounds for distinguishing between different classes of experience. The scientific question is whether or not the different classes of experience turn out to be susceptible to experimental manipulation and to differ in different groups of people in ways that are both systematic and replicable.

Two such classes of experience that have been usefully distinguished in this way by Tulving (1985) are those he defined operationally as remember and know responses. Remembering is characterized by mental time travel, by mentally recreating one's personal role in previous events and experiences. Knowing is characterized by an aware-

Preparation of this article was aided by Grant 000236225 from the Economic and Social Research Council, and we thank them for their support. We also thank Vicki Bruce for drawing our attention to the internet site that provided the facial stimuli used in Experiment 2 and Gulshin Rafiq and Cristina Ramponi, who helped with some data analyses. Correspondence should be addressed to J. Gardiner, Psychology Group, School of Cognitive and Computing Sciences, University of Sussex, Brighton, BN1 9QH, England (e-mail: johngar@cogs.susx.ac.uk). ness of the past merely as a fact, as a familiar, known fact. Previous events as well as more abstract general knowledge can be known in this sense. Tulving $(1983,1985)$ proposed that these two classes of experience are expressions of two kinds of consciousness, autonoetic and noetic, and that these two kinds of consciousness are in turn properties of different mind-brain systems, episodic and semantic memory.

In support of this proposal, there is now a wealth of evidence, particularly in recognition memory, that subjective reports of remembering and of knowing are susceptible to systematic manipulation and do differ in different groups of people. Indeed, the evidence indicates that two states of awareness are functionally independent in the sense that there are variables that influence either one or the other of them, variables that influence both of them in an opposite way, and variables that influence both of them in a similar way. There is additional evidence of significant differences between the two states of awareness in physiological measures of brain function (for a recent review, see Gardiner \& Richardson-Klavehn, 2000).

A process model largely developed by Rajaram (1996; for a review, see Rajaram, 1999) provides an alternative account of these findings. This account is not necessarily inconsistent with the different mind-brain systems theory, and it has the advantage of offering a finer grained explanation of the reasons why particular independent variables have the effects that they do. Initially, much of the earlier evidence was well summarized by the distinc- 
tion drawn between conceptual and perceptual processing in the transfer-appropriate processing framework (see, e.g., Roediger, Weldon, \& Challis, 1989). It seemed that remembering was highly influenced by variables that affect conceptual processing, like level of processing or divided versus undivided attention, and that these variables did not much influence knowing. It seemed that knowing was highly influenced by variables that affect perceptual processing, like repetition priming of test items, and that these variables did not much influence remembering. This neat mapping of the two states of awareness onto the process distinction has more recently been overturned by evidence that the relationship between the states of awareness and the two processing dimensions is more appropriately conceived as being orthogonal.

For example, Rajaram (1996) showed that certain perceptual effects occur in remembering, rather than in knowing. She manipulated size congruency between study and test in picture recognition memory. Pictures were studied in one of two sizes that were crossed with the same or different size at test. There was an effect of size congruency in that the pictures were more likely to be recognized if their size was the same at study and test. This size congruency effect occurred only in remember responses. In other studies, other similar perceptual effects on remembering have been found when the orthographic distinctiveness of words was manipulated (Rajaram, 1998). Moreover, certain conceptual variables have been found to influence knowing, such as grouping faces into similar conceptual categories (Mäntylä, 1997) or repeating different examples from the same semantic categories (Dewhurst \& Anderson, 1999). The process model has therefore been revised. The assumption now is that what is critical for remembering is the distinctiveness of processing, whether that be conceptual or perceptual distinctiveness, and that what is critical for knowing is the fluency of the processing, whether that be perceptual or conceptual fluency (Rajaram, 1999).

We describe two experiments that follow up Rajaram's (1996) demonstration of perceptual effects of size congruency on remembering in picture recognition memory. In the first experiment, depth of encoding was manipulated by comparing undivided versus divided attention, and in the second experiment it was manipulated by comparing a deep versus a shallow orienting task. On the basis of previously well-established findings, the main effects of these variables should be to affect overall recognition performance selectively in remembering and not at all in knowing (see, e.g., Gardiner, Java, \& RichardsonKlavehn, 1996; Gardiner \& Parkin, 1990). At issue is whether or not encoding depth has any impact upon awareness in relation to the effects of size congruency.

Given the previous evidence (Rajaram, 1996), the most likely outcome seems, of course, that size congruency effects will occur in remembering and not in knowing, regardless of depth of encoding. However, there are both empirical and theoretical reasons to suggest that with more impoverished encoding conditions, size congruency effects might occur in knowing. For example, Gregg and Gardiner (1994; see also Gardiner \& Gregg, 1997) presented words visually at an extremely fast rate at study, in conjunction with a highly perceptual orienting task, in a deliberate attempt to minimize elaborative encoding and hence subsequent remembering. Under those circumstances, they found that indeed there was very little subsequent remembering, and recognition instead was accompanied largely by know responses. More important, know responses showed an effect of congruency between study-test modalities. There were more know responses if the test words were presented in the visual form identical to that used at study, compared with auditory presentation of test words. Unlike the size congruency effects in remembering reported by Rajaram (1996), however, the effect of congruency between study-test modalities found by Gregg and Gardiner did not occur at all in recognition following normal encoding conditions.

The distinctiveness/fluency framework developed by Rajaram $(1996,1998)$ does not necessarily predict that with impoverished encoding conditions size congruency effects that normally occur in remembering would instead occur in knowing. But such results would considerably strengthen its assumption that the process distinction is orthogonal to the states of awareness. And they might be expected if reducing or removing the distinctive components of a variable leads the match in the remaining processes to engender fluency of processing.

Such results might also be expected from a second process model, the independence model of remembering and knowing first described by Yonelinas and Jacoby (1995; see also Jacoby, Yonelinas, \& Jennings, 1997). This model is based on a dual-process account of recognition memory according to which recognition can be accomplished by two independent processes, recollection and familiarity (Jacoby, 1991; Mandler, 1980). It is further assumed that recollection and familiarity, respectively, give rise to the states of awareness captured by remember and know responses. An underlying relationship of independence clearly implies that effects that occur only in remembering under some circumstances might under other circumstances occur only in knowing.

Until now, however, no evidence of this sort has been reported at the level of empirical outcomes. Support for the independence remember-know model has largely been based on deriving estimates of the familiarity process, particularly estimates in which the proportion of correct know responses is divided by one minus the proportion of correct remember responses. This is because the model assumes that though remembering provides a reasonably accurate estimate of the recollection process, knowing reflects the familiarity process only in the absence of recollection. For example, Yonelinas and Jacoby (1995) also manipulated size congruency, though using computer-generated geometric shapes rather than pictures. They too found that size congruency effects occurred in remember responses and not in know responses. They 
applied the independence remember-know model and therefore showed that size congruency led to increased estimates of the familiarity process (see also, e.g., Jacoby et al., 1997). ${ }^{1}$ In support of this conclusion, Yonelinas and Jacoby also showed that size congruency led to similar increases in both recollection and familiarity processes when they were estimated using Jacoby's (1991) process dissociation procedure.

In contrast with qualitatively limited theories that ascribe remembering and knowing to different memory systems or processes, a quantitatively limited theory has also been proposed according to which remembering and knowing merely reflect differences in trace strength and response criteria (e.g., Donaldson, 1996). As we shall show later, whether or not size congruency effects can occur either in remembering or in knowing also provides a critical test of this theory.

Accordingly, each of the two experiments we describe discriminates between two alternate hypotheses with respect to how the effects of size congruency influence subjective awareness. One hypothesis is that regardless of encoding depth, these effects will occur only in remembering. The other hypothesis is that under more impoverished conditions of encoding, these same effects will occur only in knowing.

\section{EXPERIMENT 1}

Following Rajaram's (1996) Experiment 2, pictures of line drawings of objects were studied and tested in one of two sizes, small or large, and picture size was manipulated orthogonally at study and test. In addition, one group of participants studied the pictures under undivided-attention conditions, and another group of participants studied the pictures under divided-attentionconditions. In the dividedattention task, participants had to monitor a sequence of auditorily recorded digits and make a manual response every time three odd-numbered digits occurred consecutively.

\section{Method}

Participants. Fifty undergraduate students at City University volunteered to take part in the experiment, many in partial fulfillment of a course credit. They were allocated arbitrarily to one of two groups of 25 .

Design and Materials. The design was a two-by-two factorial with attention (undivided vs. divided) between groups and size congruency between study and test (same vs. different) within groups. A set of 120 line drawings was selected from Snodgrass and Vanderwart's (1980) norms with the restriction that all pictures had at least an $85 \%$ name agreement score. Each of these pictures was then created in two formats, a small and a large size, for display on cards viewed on a table where participants were seated. The ratio of small to large pictures was 1:1.6.

Study lists consisted of 30 small and 30 large pictures mixed together. The test list consisted of the studied pictures mixed together with a further 30 small and 30 large pictures. Half of the studied pictures were tested in the same small or large size that had been used at study. The other half of the studied pictures were tested in the alternative size to the one used at study. A total of eight combinations of study and test lists were used to achieve full counterbalancing of items (one combination was used an extra time, for the 25th participant in each group). The presentation of the small and large pictures in study and test lists was randomly ordered with respect to size and the same study-test lists were used in each group.

The materials for the divided-attention task consisted of an audiotape in which 22 sequences of three consecutive odd numbers occurred within a string of 130 apparently random digits. There were several restrictions. No more than three odd numbers ever occurred consecutively, and all numbers ranged from 0 to 20 . The number of digits between the sets of three consecutive odd numbers ranged from one to five. The digits were recorded at a 2 -sec rate.

Procedure. Participants were tested individually. They were all told that they would see a series of line drawings of objects that would be involved in a later (unspecified) memory test. They were all told to attend to the position of the picture in relation to the card on which it was displayed and to write down whether it was nearer the top or the bottom of the card. The pictures were presented at a 4-sec rate. Participants in the divided-attention groups were additionally instructed about the divided-attention task. The importance of not missing a sequence of three consecutive odd numbers was stressed. Participants' accuracy was monitored by the experimenter, and they were prompted if sequences were missed. Participants reported the occurrence of a sequence by tapping the table in front of them. On average, participants failed to detect 3.8 of the 22 target sequences. Three participants who appeared unable or unwilling to perform this task were replaced.

There was a retention interval after the presentation of the study lists during which participants were given an anagram-solving task. This interval lasted for $20 \mathrm{~min}$. Participants were then given instructions for the recognition test, including the remember and know responses. They were told that they would be shown a series of pictures that would be either small or large in size and that some of these pictures had been shown at study, but not necessarily in the same size. These pictures were again shown on cards. The participants were told to ignore the size of the picture in making their recognition and remember and know responses. As in most previous studies, participants first made old versus new decisions followed by remember or know responses if the decision was old (see Hicks \& Marsh, 1999). The full instructions for recognition, remember, and know responses were closely modeled on those used by Rajaram (1996) as published in an appendix to her article. Guessing was discouraged by the instruction to "write $\mathrm{K}$ (for know) when you are certain of recognizing the pictures but these pictures fail to evoke any specific conscious recollection from the study list." Participants recorded their responses in writing on an answer sheet with the serial numbers of the test items. These numbers were called out by the experimenter, who monitored the participants' progress and presented the next picture only when responses to the previous picture had been completed. Allowing for instructions, the test began about $30 \mathrm{~min}$ after the study phase and lasted about $20 \mathrm{~min}$.

\section{Results and Discussion}

The proportions of correct remember, know, and recognize (remember plus know) responses are summarized in Table 1 . Several trends in these data are readily appar-

Table 1

Mean Proportions of Correct Responses, and Standard Deviations, as a Function of Attention

\begin{tabular}{|c|c|c|c|c|c|c|c|c|}
\hline \multirow{3}{*}{$\begin{array}{l}\text { Response } \\
\text { Category }\end{array}$} & \multicolumn{4}{|c|}{ Undivided Attention } & \multicolumn{4}{|c|}{ Divided Attention } \\
\hline & \multicolumn{2}{|c|}{ Same Size } & \multicolumn{2}{|c|}{ Different Size } & \multicolumn{2}{|c|}{ Same Size } & \multicolumn{2}{|c|}{ Different Size } \\
\hline & $M$ & $S D$ & $M$ & $S D$ & $M$ & $S D$ & $M$ & $S D$ \\
\hline Rem & .53 & .14 & .37 & .09 & .15 & .06 & .12 & .06 \\
\hline Know & .26 & .10 & .27 & .09 & .34 & .11 & .22 & .11 \\
\hline Recognize & .79 & .11 & .64 & .10 & .49 & .10 & .34 & .10 \\
\hline
\end{tabular}


ent. The size congruency effect was replicated in overall recognition responses, where it occurred to a similar extent in the divided-attention condition as in the undividedattention condition. But this effect was largely restricted to remember responses with undivided attention, as Rajaram (1996) found (see also Yonelinas \& Jacoby, 1995), and with divided attention this same effect was largely restricted to know responses. The overall effect of divided attention was to reduce correct recognition, but only selectively for remember responses, as found in other previous studies involving word lists (Gardiner \& Parkin, 1990) and pictures of faces (Parkin, Gardiner, \& Rosser, 1995). The false alarm rates for recognition decisions were .12 in the undivided-attention condition .03 remember, $.09 \mathrm{know})$ and .10 in the divided-attention condition (.03 remember, $.07 \mathrm{know}$ ). These false alarm rates are relatively low, quite similar, and typical of those found in most previous studies except a few in which participants have either by instruction or by choice adopted very lenient response criteria.

The significance level here and in the following experiment was set at $p<.05$. Separate analyses of variance (ANOVAs) were carried out on proportions correct for each of the three kinds of responses: remember, know, and recognize (remember plus know). The factors were attention (undivided vs. divided) and size congruency (same size vs. different size). For remember responses, both the main effect of attention $[F(1,96)=264.46$, $\left.M S_{\mathrm{e}}=.01\right]$ and the main effect of size congruency $\left[F(1,96)=22.48, M S_{\mathrm{e}}=.01\right]$ were significant, and so too was the interaction between them $[F(1,96)=11.39$, $\left.M S_{\mathrm{e}}=.01\right]$. For know responses, the main effect of attention was not significant $[F<1]$, but the main effect of size congruency was significant $\left[F(1,96)=6.42, M S_{\mathrm{e}}=\right.$ $.01]$, and so too was the interaction between them $\left[F(1,96)=10.07, M S_{\mathrm{e}}=.01\right]$. For recognize responses, both the main effect of attention $[F(1,96)=194.77$, $\left.M S_{\mathrm{e}}=.01\right]$ and the main effect of size congruency $\left[F(1,96)=47.43, M S_{\mathrm{e}}=.01\right]$ were significant, but the interaction between them was not $[F<1]$.

These results confirm that with undivided attention, the size congruency effect occurred only in remembering, and with divided attention, the size congruency effect occurred only in knowing. It is additionally worth noting that these effects of size congruency were highly consistent across participants. In the undivided-attention group, 23 of the 25 participants showed the effect in remember responses. In the divided-attention group, 19 of 24 participants showed the effect in know responses (with one tie).

\section{EXPERIMENT 2}

Experiment 2 was designed to replicate and extend the results obtained in Experiment 1. Size congruency at study and test was again manipulated, but instead of pictures of objects, photographs of faces were used. Encoding was again manipulated but instead of comparing undivided with divided attention, we manipulated level of processing by comparing a deep with a shallow orienting task. The deep orienting task involved making a judgment about the honesty and likeableness of the person's face-how "reliable" the person looked. The shallow orienting task involved making a judgment about the person's gender (see, e.g., Bower \& Karlin, 1974).

\section{Method}

Participants. Forty undergraduate or postgraduate students at City University volunteered to take part in the experiment, many in partial fulfillment of a course credit. They were allocated arbitrarily to one of two groups of 20 except that each group included 10 female and 10 male participants.

Design and Materials. The design was a two-by-two factorial with level of processing (deep vs. shallow) between groups and size congruency between study and test (same vs. different) within groups. A set of 120 black-and-white photographs of unfamiliar Caucasian faces were selected from an Internet site provided by Stirling University (http.//pics.psych.stir.ac.uk/ index.html) and printed out separately. Half of these were female faces and half were male faces. Other distinguishing characteristics, such as glasses, jewelry, and facial hair, were avoided. Each face had been pictured against a neutral background in full frontal view and with a neutral expression. Each of the faces was enlarged by $56 \%$ so as to create alternate small and large versions that were mounted individually on cards.

Study lists consisted of 30 small and 30 large faces mixed together. The test list consisted of the studied pictures mixed together with a further 30 small and 30 large faces. There were 15 female and 15 male faces within each set of 30 . Half the studied faces were tested in the same small or large size that had been used at study. The other half of the faces were tested in the alternative size to the one used at study. A total of eight combinations of study and test lists were used to achieve full counterbalancing of items (four combinations were used an extra time, for the last 4 participants in each group). The presentation of the small and large faces in study and test lists was randomly ordered with respect to size and gender, and the same study-test lists were used in each group.

Procedure. Participants were tested individually or 2 or 3 at a time. They were all told that they would see a series of photographs of faces that would be involved in a later (unspecified) memory test and that they had to make certain judgments about the people whose faces they were going to see. The faces were presented at a 5-sec rate. Participants in one group had to rate each person's face on a 5-point scale according to how "reliable" or "unreliable" they thought the person looked $(1=$ very reliable $; 5=$ very unreliable $)$ and to record their ratings on a numbered answer sheet. Participants in the other group were required simply to state (out loud) whether the face was that of a female or of a male. Other aspects of the procedure were similar to that of Experiment 1, including the filled retention interval, the administration of the recognition test, and the instructions for recognition, remember, and know responses.

\section{Results and Discussion}

The proportions of correct remember, know, and recognize (remember plus know) responses are summarized

Table 2

Mean Proportions of Correct Responses, and Standard Deviations, as a Function of Level of Processing

\begin{tabular}{|c|c|c|c|c|c|c|c|c|}
\hline \multirow{3}{*}{$\begin{array}{l}\text { Response } \\
\text { Category }\end{array}$} & \multicolumn{4}{|c|}{ Deep Level } & \multicolumn{4}{|c|}{ Shallow Level } \\
\hline & \multicolumn{2}{|c|}{ Same Size } & \multicolumn{2}{|c|}{ Different Size } & \multicolumn{2}{|c|}{ Same Size } & \multicolumn{2}{|c|}{ Different Size } \\
\hline & $M$ & $S D$ & $M$ & $S D$ & $M$ & $S D$ & $M$ & $S D$ \\
\hline $2 \mathrm{em}$ & .54 & .15 & .33 & .08 & 12 & .07 & .10 & .08 \\
\hline Kno & .22 & .13 & .20 & .11 & .31 & .09 & .1 & .07 \\
\hline Recognize & .76 & .15 & .53 & .09 & .43 & .11 & .23 & .09 \\
\hline
\end{tabular}


in Table 2. Several trends in these data are readily apparent. The size congruency effect was replicated again in overall recognition responses, where it occurred to much the same extent following the shallow orienting task as following the deep orienting task. But this effect was largely restricted to remember responses with the deeper level of processing, and with the shallower level of processing this same effect was largely restricted to know responses. The overall effect of level of processing was to reduce correct recognition, but only selectively for remember responses, as found in previous studies involving word lists (e.g., Gardiner, 1988; Gardiner et al., 1996). The false alarm rates for recognition decisions were .10 for the deeper orienting task (.04 remember, .06 know) and .09 for the shallow orienting task (.04 remember, .05 know). These false alarm rates are again relatively low and quite similar.

Separate ANOVAs were carried out on proportions correct for each of the three kinds of response: remember, know, and recognize (remember plus know). The factors were level of processing (deep vs. shallow) and size congruency (same size vs. different size). For remember responses, both the main effect of level of processing $\left[F(1,76)=145.98, M S_{\mathrm{e}}=.01\right]$ and the main effect of size congruency $\left[F(1,76)=29.42, M S_{\mathrm{e}}=.01\right]$ were significant, and so too was the interaction between them $\left[F(1,76)=19.81, M S_{\mathrm{e}}=.01\right]$. For know responses, the main effect of level of processing was not significant $[F<1]$, but the main effect of size congruency was significant $\left[F(1,76)=8.80, M S_{\mathrm{e}}=.01\right]$, and so too was the interaction between them $\left[F(1,76)=7.54, M S_{\mathrm{e}}=.01\right]$. For recognize responses, both the main effect of level of processing $\left[F(1,76)=97.50, M S_{\mathrm{e}}=.01\right]$ and the main effect of size congruency $\left[F(1,76)=30.89, M S_{\mathrm{e}}=.01\right]$ were significant, but the interaction between them was $\operatorname{not}[F<1]$.

These results confirm that with the deep level of processing, the size congruency effect occurred only in remembering and with the shallow level of processing, the size congruency effect occurred only in knowing. These effects of size congruency were again highly consistent across participants. In the deep processing group, 16 of 19 participants showed the effect in remember responses (with one tie). And in the shallow processing group, 18 of 20 participants showed the effect in know responses.

\section{GENERAL DISCUSSION}

In each of two experiments the effects of size congruency in remembering were replicated (Rajaram, 1996; see also Yonelinas \& Jacoby, 1995). These effects on remembering, however, occurred only with full attention and with deeper level of processing at encoding. With divided attention and with shallow processing at encoding, the effects of size congruency occurred not in remembering but in knowing. Overall recognition performance showed no interaction between depth of encoding and size congruency, but quite different interactions were evident in the two states of awareness.

The discovery that the same size congruency effects that occur in remembering can also occur independently in knowing is relevant to a number of theoretical accounts. Within the distinctiveness/fluency framework developed by Rajaram $(1996,1998)$ these results support previous conclusions about perceptual effects in remembering. And by showing how the same effects can disappear from remembering and reappear in knowing, they strengthen the argument that the process distinction is orthogonal to the awareness distinction. Following optimal encoding conditions, size congruency presumably allows greater reinstatement at test of the more elaborative, and hence more distinctive, features of the pictured object or face. Following impoverished encoding conditions, processing of that kind is largely prevented, and the effects of size congruency reflect instead processing fluency.

By showing that the same effects may occur either in remembering or in knowing, our results also provide some support for the independence remember-know model (Jacoby et al., 1997; Yonelinas \& Jacoby, 1995). Estimates of the familiarity process in this model are derived from the proportions of correct know responses divided by one minus the proportions of correct remember responses. The proportions of remember and know responses for same versus different size from Table 1 indicate that these familiarity estimates are, respectively, .55 versus .43 for undivided attention and .40 versus .25 for divided attention. The corresponding estimates from Table 2 are .48 versus .30 for the deep level and .35 versus .14 for the shallow level. Thus in contrast with what happens following optimal encoding conditions, following impoverished encoding conditions the estimates of the familiarity process converge with what is observed empirically in know responses.

But though the present results may provide some support for the independence remember-know model, a number of other results do not. The problems have been discussed at length elsewhere (see Gardiner, 2000; Gardiner \& Richardson-Klavehn, 2000; Richardson-Klavehn, Gardiner, \& Java, 1996). One particular problem stems from the additional assumption that the familiarity process is automatic and relatively fast and that the recollection process is effortful and relatively slow. Using a response deadline procedure, Gardiner, Ramponi, and Richardson-Klavehn (1999) showed that in fact both knowing and remembering increase similarly with longer response deadlines, indicating that both states of awareness are effortful and under some degree of conscious control. Furthermore, even applying the independence remember-know model to these findings did not bring the results into line with the predictions of the dual-process model (see Gardiner et al., 1999).

The independence model suggests that effects normally observed in remember but not in know responses might generally occur in know responses whenever the propor- 
tions of remember responses are sufficiently reduced. Previous studies have shown no evidence that effects that normally occur in remembering emerge in know responses with low as opposed to high numbers of remember responses (see, e.g., Dewhurst \& Anderson, 1999; Gardiner \& Parkin, 1990; Gardiner \& Radomski, 1999). The relative proportions of the two kinds of responses do not generally seem to influence the effects of a manipulated variable.

It is in fact possible that the kinds of effects observed in the present experiments may be quite circumscribed. For example, Curran and Hildebrandt (1999) manipulated two encoding variables-generating compared with reading study list words and psychopharmacological drug state. Participants had either been given a dose of alcohol or a placebo before studying the list. Alcohol reduced recognition performance substantially and selectively for remember but not know responses. It also greatly attenuated the generation effect, which as usual occurred only in remember responses (see, e.g., Gardiner, 1988; Gardiner et al., 1996). There were no indications at all of a generation effect emerging in know responses.

In order to retain continuity with Rajaram's (1996) experiments, participants in the present experiments were allowed only remember and know responses. Elsewhere we have argued that a "remember-know-guess paradigm" has considerable advantages (Gardiner \& RichardsonKlavehn, 2000). In this paradigm, "guess" becomes the default response, and participants are instructed to report a guess if they have some strategic reason to suspect that a test item was a target even though it does not give rise to experiences of remembering or knowing. Guess responses are informed by what participants have learned about the characteristics of the experiment as a whole, including the general nature of study and test items (see Gardiner, Ramponi, \& Richardson-Klavehn, 1998). Where guess responses have been used, it has been generally found that participants do not show any memory for the specific items that elicit them. Indeed, guess responses to lure items often exceed guess responses to target items, presumably because of differential response opportunity. Moreover, where participants' response criteria have been relatively lenient, the evidence shows that it is guess responses that are inversely related to remember responses, with know responses being largely unaffected (e.g., Gardiner \& Conway, 1999). Like the present findings, this evidence provides no support for the idea that there is in general an inverse relation between the amount of remembering observed and the emergence of effects in knowing.

The present results also have some implications for Tulving's (1995) SPI model of relations between semantic and episodic systems. In this model, encoding is serial (S), storage is parallel (P), and retrieval is independent (I). Events can be encoded into the semantic system without being encoded into the episodic system, but they cannot be encoded into the episodic system without being encoded into the semantic system. It is well established that encoding into the episodic system depends greatly on the extent to which the events are elaborated upon consciously at the time of their occurrence (see, e.g.,
Gardiner \& Richardson-Klavehn, 2000). With full attention and with a deep level of processing, there is good opportunity for such conscious elaboration. With divided attention and with a shallow level of processing, the opportunity for such conscious elaboration is greatly reduced. Under those conditions it is more likely that events are encoded into the semantic system but not into the episodic system. On this view, the findings show that size congruency has similar encoding specificity effects in both semantic and episodic systems.

The final theoretical account that we discuss is a trace strength account, according to which remember responses reflect stronger traces and more stringent response criteria, and know responses reflect weaker traces and more lenient response criteria (Donaldson, 1996; Hirshman \& Master, 1997; Inoue \& Belleza, 1998). In this model, response criteria can be placed along a single continuum of trace strength in ways that apparently allow it to mimic the patterns of dissociation and association that have been observed in the literature between remember and know responses. As Donaldson pointed out, the most critical test of this model's goodness of fit is not that there should be differences in response criteria but that estimates of trace strength should be the same irrespective of the response criteria used in deriving them. Although some experimental data seem to fit this model (see, e.g., Gardiner et al., 1999; Hirshman \& Henzler, 1998), a great deal of data are in fact at variance with it (see, e.g., Gardiner \& Conway, 1999; Gardiner \& Gregg, 1997; Gardiner, Ramponi, \& Richardson-Klavehn, 1998; Gardiner, RichardsonKlavehn, \& Ramponi, 1998). Perhaps the greatest difficulty for this model is presented by evidence of differences in awareness, as measured by remember and know responses, in the absence of any differences in recognition performance. There is evidence of this kind in several previous studies (see Blaxton \& Theodore, 1997; Bowler, Gardiner, \& Grice, 2000; Conway \& Dewhurst, 1995; Conway, Dewhurst, Pearson, \& Sapute, in press). Our findings add to this evidence. Depth of encoding influenced size congruency effects in terms of the states of awareness, not in terms of the proportions of correct recognition scores. Nor was there any evidence that these similar effects of size congruency on correct recognition at each depth of encoding were accompanied by differences in false alarm rates. Differences in false alarm rates would be expected if the effects were related to differences in response criteria. In addition, we carried out a signal detection analysis of the results from Experiments 1 and 2. This analysis is described in Appendix A. In a further refutation of this trace strength account, the analysis showed that estimates of trace strength were consistently greater when derived from overall recognition scores than when derived from only remember responses.

The results of the two experiments described in this article provide empirical evidence that effects that occur in remembering may also occur independently in knowing. Our conclusion is that these results support qualitatively limited theories in which remembering and knowing are viewed as reflecting different memory processes 
or systems. They do not support a quantitatively limited theory in which remembering and knowing are viewed as reflecting differences in trace strength.

\section{REFERENCES}

Blaxton, T. A., \& Theodore, W. H. (1997). The role of the temporal lobes in recognizing visuospatial materials: Remembering versus knowing. Brain \& Cognition, 35, 5-25.

Bower, G. H., \& Karlin, M. B. (1974). Depth of processing pictures of faces and recognition memory. Journal of Experimental Psychology, 103, 751-757.

Bowler, D. M., Gardiner, J. M., \& Grice, S. (2000). Episodic memory and remembering in adults with Aspberger's syndrome. Journal of Autism \& Developmental Disorders, 30, 295-304.

Conway, M. A., \& Dewhurst, S. A. (1995). The self and recollective experience. Applied Cognitive Psychology, 9, 1-19.

Conway, M. A., Dewhurst, S. A., Pearson, N., \& Sapute, A. (in press). The self and recollection reconsidered: How a "failure to replicate" failed and why current trace strength accounts of remembering are untenable. Applied Cognitive Psychology.

Curran, H. V., \& Hildebrandt, M. (1999). Dissociative effects of alcohol on recollective experience. Consciousness \& Cognition, 8, 497-509.

Dewhurst, S. J., \& ANDERson, S. J. (1999). Effects of exact and category repetition in true and false recognition memory. Memory \& Cognition, 27, 665-673.

Donaldson, W. (1996). The role of decision processes in remembering and knowing. Memory \& Cognition, 24, 523-533.

Gardiner, J. M. (1988). Functional aspects of recollective experience. Memory \& Cognition, 16, 309-313.

GARDINER, J. M. (2000). On the objectivity of subjective experiences of autonoetic and noetic consciousness. In E. Tulving (Ed.), Memory, consciousness, and the brain: The Tallinn conference (pp. 159-172). Philadelphia: Psychology Press.

GARDiner, J. M., \& Conway, M. A. (1999). Levels of awareness and varieties of experience. In B. H. Challis \& B. M. Velichkovsky (Eds.), Stratification of consciousness and cognition (pp. 237-254). Amsterdam: John Benjamin.

GARDINER, J. M., \& GREgG, V. H. (1997). Recognition memory with little or no remembering: Implications for a detection model. Psychonomic Bulletin \& Review, 4, 474-479.

Gardiner, J. M., JaVA, R. I., \& RichardSON-KlaVehn, A. (1996). How level of processing really influences awareness in recognition memory. Canadian Journal of Experimental Psychology, 50, 114-122.

Gardiner, J. M., \& Parkin, A. J. (1990). Attention and recollective experience in recognition memory. Memory \& Cognition, 18, 579-583.

GARDINER, J. M., \& RADOMSKI, E. (1999). Awareness of recognition memory for Polish and English folksongs in Polish and English folk. Memory, 7, 461-470.

Gardiner, J. M., Ramponi, C., \& Richardson-Klavehn, A. (1998). Experiences of remembering, knowing, and guessing. Consciousness \& Cognition, 7, 1-26.

Gardiner, J. M., Ramponi, C., \& Richardson-Klavehn, A. (1999). Response deadline and subjective awareness in recognition memory. Consciousness \& Cognition, 8, 484-496.

Gardiner, J. M., \& RichardSON-KLAVEhN, A. (2000). Remembering and knowing. In E. Tulving \& F. I. M. Craik (Eds.), Handbook of memory (pp. 229-244). New York: Oxford University Press.

Gardiner, J. M., Richardson-Klavehn, A., \& Ramponi, C. (1998). Limitations of the signal detection model of the remember-know paradigm: A reply to Hirshman. Consciousness \& Cognition, 7, 285-288.

GregG, V. H., \& Gardiner, J. M. (1994). Recognition memory and awareness: A large effect of study-test modalities on "know" responses following a highly perceptual orienting task. European Journal of Cognitive Psychology, 6, 137-147.

Hicks, J. L., \& MARsh, R. L. (1999). Remember-know judgments can depend on how memory is tested. Psychonomic Bulletin \& Review, 6, 117-122.

Hirshman, E., \& Henzler, A. (1998). The role of decision processes in conscious recollection. Psychological Science, 9, 61-65.

Hirshman, E., \& MASTER, S. (1997). Modeling the conscious correlates of recognition memory: Reflections on the remember-know paradigm. Memory \& Cognition, 25, 345-351.

Inoue, C., \& Bellezza, F. S. (1998). The detection model of recognition using know and remember judgements. Memory \& Cognition, 26, 299-308

JACOBY, L. L. (1991). A process-dissociation framework: Separating automatic from intentional uses of memory. Journal of Memory \& Language, 30, 513-541.

JAcoby, L. L., Yonelinas, A. P., \& Jennings, J. M. (1997). The relation between conscious and unconscious (automatic) influences: A declaration of independence. In J. D. Cohen \& J. W. Schooler (Eds.), Scientific approaches to the question of consciousness (pp. 13-47) Hillsdale, NJ: Erlbaum.

MANDLER, G. (1980). Recognizing: The judgment of previous occurrence. Psychological Review, 87, 252-271.

MäNTY LÄ, T. (1997). Recollection of faces: Remembering differences and knowing similarities. Journal of Experimental Psychology: Learning, Memory, \& Cognition, 23, 1203-1216.

Parkin, A. J., Gardiner, J. M., \& Rosser, R. (1995). Functional aspects of recollective experience in face recognition. Consciousness \& Cognition, 4, 387-398.

Rajaram, S. (1996). Perceptual effects on remembering: Recollective processes in picture recognition memory. Journal of Experimental Psychology: Learning, Memory, \& Cognition, 22, 365-377.

RAJARAM, S. (1998). Conceptual and perceptual effects on remembering: The role of salience/distinctiveness. Psychonomic Bulletin \& Review, 5, 71-78.

RAJARAM, S. (1999). Assessing the nature of retrieval experience: Advances and challenges. In B. H. Challis \& B. M. Velichkovsky (Eds.), Stratification of consciousness and cognition (pp. 255-275). Amsterdam: John Benjamin.

Richardson-Klavehn, A., Gardiner, J. M., \& JaVA, R. I. (1996). Memory: Task dissociations, process dissociations, and dissociations of consciousness. In G. Underwood (Ed.), Implicit cognition (pp. 85158). Oxford: Oxford University Press.

Roediger, H. L., Weldon, M. S., \& Challis, B. H. (1989). Explaining dissociations between implicit and explicit measures of retention: A processing account. In H. L. Roediger III \& F. I. M. Craik (Eds.), Varieties of memory and consciousness: Essays in honour of Endel Tulving (pp. 3-41). Hillsdale, NJ: Erlbaum.

SEARLE, J. R. (1997). The mystery of consciousness. London: Granta. Snodgrass, J. G., \& VANDERWART, M. (1980). A standardized list of 260 pictures: Norms for name agreement, image agreement, familiarity, and visual complexity. Journal of Experimental Psychology: Human Learning \& Memory, 6, 174-215.

Tulving, E. (1983). Elements of episodic memory. Oxford: Oxford University Press.

Tulving, E. (1985). Memory and consciousness. Canadian Psychology, 26, 1-12.

Tulving, E. (1995). Organization of memory: Quo vadis? In M. S. Gazzaniga (Ed.), The cognitive neurosciences (pp. 839-847). Cambridge, MA: MIT Press.

YonelinAS, A. P., \& JACOBY, L. L. (1995). The relation between remembering and knowing as bases for recognition: Effects of size congruency. Journal of Memory \& Language, 34, 622-643.

\section{NOTE}

1. Note, however, that in Yonelinas and Jacoby's (1995) experiments, know responses to old items did not differ much from know responses to new items. Usually, know responses to old items reliably exceed know responses to new items (see Gardiner \& Conway, 1999). 


\section{APPENDIX A}

In this appendix we briefly present a signal detection analysis of the results of Experiments 1 and 2 and discuss its implications. The analysis follows that recommended by Donaldson (1996), who argued that with data of this sort, estimates of the strength of the memory trace should be derived using $A^{\prime}$ rather than $d^{\prime}$ because $A^{\prime}$ is less susceptible than $d^{\prime}$ to differences in response criteria (see also Gardiner \& Conway, 1999; Gardiner \& Gregg, 1997). $A^{\prime}$ estimates normally vary between .5 , which represents chance, and 1.0, which represents perfect memory. The corresponding estimates of response criteria are given by $B_{D}^{\prime \prime}$, which normally varies between 1.0 , which represents the most stringent criterion, and -1.0 , which represents the most lenient criterion. The most critical prediction for the model is not that there will be differences in response criteria but that the strength of the memory trace should be the same regardless of the response criteria used to estimate it.

In experiments that include only remember and know responses, there are two sets of response criteria: those associated with remember responses and those associated with overall recognition-that is, remember plus know responses. Tests of the critical prediction have generally found that $A^{\prime}$ estimates are reliably greater when derived from overall recognition scores than when derived from only remember responses. This result has been found both in meta-analyses of the results of many experiments and in analyses of estimates derived from individual participants (see Gardiner \& Conway, 1999; Gardiner \& Gregg, 1997). That outcome refutes the signal detection model because it indicates an increase in the strength of the memory "signal" when know responses are added to remember responses. That outcome supports instead dual-component theories that attribute know responses to an additional source of memory.

Table A1

Mean $A^{\prime}$ and $B_{D}^{\prime \prime}$ Estimates as a Function of Attention

\begin{tabular}{|c|c|c|c|c|c|c|c|c|}
\hline \multirow{3}{*}{$\begin{array}{l}\text { Response } \\
\text { Category }\end{array}$} & \multicolumn{4}{|c|}{ Undivided Attention } & \multicolumn{4}{|c|}{ Divided Attention } \\
\hline & \multicolumn{2}{|c|}{$\underline{\text { Same Size }}$} & \multicolumn{2}{|c|}{ Different Size } & \multicolumn{2}{|c|}{$\underline{\text { Same Size }}$} & \multicolumn{2}{|c|}{ Different Size } \\
\hline & $A^{\prime}$ & $B_{D}^{\prime \prime}$ & $A^{\prime}$ & $B_{D}^{\prime \prime}$ & $A^{\prime}$ & $B_{D}^{\prime \prime}$ & $A^{\prime}$ & $B_{D}^{\prime \prime}$ \\
\hline Remember & .86 & .95 & .82 & .97 & .75 & .99 & .73 & .99 \\
\hline Recognize & .91 & .26 & .86 & .62 & .82 & .82 & .76 & .89 \\
\hline
\end{tabular}

Table A2

Mean $A^{\prime}$ and $B_{D}^{\prime \prime}$ Estimates as a Function of Level of Processing

\begin{tabular}{|c|c|c|c|c|c|c|c|c|}
\hline \multirow{3}{*}{$\begin{array}{l}\text { Response } \\
\text { Category }\end{array}$} & \multicolumn{4}{|c|}{ Deep Level } & \multicolumn{4}{|c|}{ Shallow Level } \\
\hline & \multicolumn{2}{|c|}{ Same Size } & \multicolumn{2}{|c|}{ Different Size } & \multicolumn{2}{|c|}{ Same Size } & \multicolumn{2}{|c|}{ Different Size } \\
\hline & $A^{\prime}$ & $B_{D}^{\prime \prime}$ & $A^{\prime}$ & $\overline{B_{D}^{\prime \prime}}$ & $\overline{A^{\prime}}$ & $B_{D}^{\prime \prime}$ & $\overline{A^{\prime}}$ & $B_{D}^{\prime \prime}$ \\
\hline Remember & .86 & .88 & .77 & .96 & .71 & .99 & .67 & .99 \\
\hline Recognize & .90 & .36 & .84 & .70 & .81 & .72 & .74 & .86 \\
\hline
\end{tabular}

Tables A1 and A2 summarize mean $A^{\prime}$ estimates derived from individual participantdata in Experiments 1 and 2 together with the corresponding $B_{D}^{\prime \prime}$ estimates of response criteria. The crucial finding in Tables $\mathrm{A} 1$ and $\mathrm{A} 2$ is that the $A^{\prime}$ estimates are consistently greater when derived from overall recognition scores than when derived only from remember responses, replicating results generally found in previous studies (Gardiner \& Conway, 1999; Gardiner \& Gregg, 1997). Statistical analyses of the individual participant data confirmed that this difference between the two sets of estimates was highly significant $[F(1,48)=$ $60.12, M S_{\mathrm{e}}=.01$ in Experiment 1 and $F(1,38)=31.62, M S_{\mathrm{e}}=$ .02 in Experiment 2]. The $A^{\prime}$ estimates were also reliably greater for same than for different size at study and test [Experiment 1: $F(1,48)=75.82, M S_{\mathrm{e}}=.01$; Experiment $2: F(1,38)=35.20$, $\left.M S_{\mathrm{e}}=.02\right]$. The effects of size congruency were very similar on estimates derived from overall recognition scores at each depth of encoding. Its effects were, however, appreciably greater on estimates derived from remember responses with deeper encoding relative to impoverished encoding, and reliably so in a combined analysis of estimates from both experiments, if not in separate analyses of them $\left[F(1,86)=4.85, M S_{\mathrm{e}}=.03\right]$.

The corresponding $B_{D}^{\prime \prime}$ estimates of response criteria are less important theoretically. They are more or less at ceiling for remember responses and lower for overall recognition, especially with greater encoding depth and same size at study and test. It is of course questionable whether it is even legitimate to carry out such a signal detection analysis when one of the two response criteria is almost invariably at ceiling and the other is strongly constrained by instructions to respond only when certain of recognizing the test items. But this situation is typical of most if not all remember-know studies in the literature. 